\title{
Improving Unsupervised Stemming by using Partial Lemmatization Coupled with Data-based Heuristics for Hindi
}

\author{
Deepa Gupta \\ Amrita Vishwa Vidyapeetham \\ Amrita School of Engineering \\ Bangalore, India
}

\author{
Rahul Kumar Yadav \\ Amrita Vishwa Vidyapeetham \\ Amrita School of Engineering \\ Bangalore, India
}

\author{
Nidhi Sajan \\ Amrita Vishwa Vidyapeetham \\ Amrita School of Engineering \\ Bangalore, India
}

\begin{abstract}
Stemming and Lemmatization are two important natural language processing techniques widely used in Information Retrieval (IR) for query processing and in Machine Translation (MT) for reducing the data sparseness. Both minimize inflectional forms, and sometimes derivationally related forms of a word, to a common base form. Most of the existing stemmer and lemmatization work is based either on some language dependent rules which require the supervision of a language expert, or some probabilistic approach that needs vast amount of monolingual corpus, both of which develop stemming and lemmatization algorithms independently. In our work, we propose an unsupervised stemming which is hybridized with partial lemmatization for Hindi. The stemmer proposed is unique in that it exploits a novel grouping criteria \& aims to improve unsupervised stemming and most importantly avoid over-stemming problem which is a usual phenomena in stemming. The later is tackled by the introduction of lemma. We incorporated lemmatization based on data heuristics obtained from the corpus, without the use of word class information. Application of this concept to unsupervised stemming yielded significant improvements in the desired results when compared to other prevailing approaches of its genre.
\end{abstract}

\section{General Terms}

Natural Language Processing

\section{Keywords}

Stemming, Lemmatization, Hindi, Over-stemming, Understemming, Clustering, Data-based heuristics.

\section{INTRODUCTION}

Since the day man realized the importance of information, storing and retrieving the same became necessary. The advent of computers increased the amount of electronic data that can be stored. IR is essentially the requirement of documents in a collection that should be retrieved to satisfy a user's need for information. The user's information requirement is represented by a query or profile, and contains one or more search terms. The search terms may take different morphological variations. This is because in a natural language a word can assume a variety of morphological variations which can be attributed solely to the process of inflation or derivation. For instance, 'reduce' may be used as reduce, reduced, or reduction. Hence the need for some kind of natural language processing in order to recognize their equivalent form \& reduce of the variants to a common base word or stem which improves the performance of IR[7]. The processing can exploit stemming or lemmatization as its tool.

Stemming reduces the words to the common stem merely by truncation i.e. chopping off the unnecessary morpheme (suffix). They are not considerate about the grammatical rules of the language. For example, the collection of words viz. 'produce', 'produced', 'producing' and 'production' are stemmed to a common word 'produc-'. While above is the case with stemming, Lemmatization removes the inflectional endings and returns the base or dictionary form of the word. The lemma for the above example is 'produce'. It is closely related to stemming with a difference that the stemmer operates on a single word without the knowledge of the context, and therefore does not consider the parts of speech.

The stemming is normally exposed to two problems viz. over-stemming and under-stemming [3]. Over-stemming is said to have occurred when words that are not morphological variants are conflated. Alternatively, it occurs in case of conflation of semantically distant words. An example in English would be, 'compile' and 'compute' getting stemmed to 'comp-'. Under-stemming occurs when two semantically exact words which may be differently inflected should be stemmed. Evidently, under stemming occurs when words that are morphological variants are not conflated. For instance, 'compile' \& 'compiling' get stemmed to 'compil-'. Though under stemming limits the reduction in the size of the data index for IR, it is not an alarming issue compared to overstemming. Over stemming exhibits the potential of misleading the user by producing irrelevant stems \& there by retrieving inaccurate \& probably wrong results. For example, consider the following set of words of Hindi: कहानी, कहानियाँ, कहानियो, कहावत, कहावतो, कहावते. Stemming reduces all the above words to कहा. Clearly, for a search of कहावत which translates to 'sayings or quotes', or कहानी which means 'story', the IR system shall produce documents pertaining to कहा which is 'to say'.

Stemmers and Lemmatizers are available for English and other European languages but are not easily/freely available for India languages, particularly for Hindi. Hindi is the official language of India, and is the most widely spoken Indo-Aryan language (in India) with about 487 million speakers. With the proliferation of the Internet in south Asian countries over the last decade, the presence of the Hindi community on the World Wide Web has become significant 
online resources. Thus there arises a need for rather accurate information retrieval of Hindi documents. Hence we propose an unsupervised stemming algorithm which is partially fused with lemmatization \& then exploits only the corpus for the heuristics to do the needful. Lemma is introduced to deal with the problem of over-stemming, which in effect improves the stemming quality. We incorporated Lemmatization in the stemming algorithm.

The remainder of this paper is organized as follows. Section 2 presents a description in brief about some of the stemming and Lemmatization algorithms proposed thus far. The algorithm developed by us is dealt with in Section 3. Its subsections describe the steps with the sample examples. Section 4 introduces the details of the corpus used for the validation of our algorithm. Section 5 deals with the statistics obtained from the experimentation we performed using our algorithm \& linguistica on the corpus. Section 6 introduces the heuristics coined \& deployed by us to improve the quality of the undertaken task. Section 7 explains the results \& analyses the obtained statistics that describe the accuracy of our algorithm. We conclude the paper by posting our conclusion \& few remarks along with the directions of our future work in Section 8.

\section{BRIEF REVIEW OF THE PAST WORKS}

Many algorithms have already been developed for stemming and lemmatization. Especially for English and other European languages [1], immense improvements have been achieved in the last few decades. On contrary, not much work has been reported for stemming for Indian languages. Also, nearly no reliable stemmer or lemmatizer exists for South Asian languages, particularly for Hindi, as it does for English \& other European languages. Besides, the concept of fusing lemmatization with unsupervised stemming has never been explored thus far. The process of stemming is achieved mainly by three popular methods. The first is based on probabilistic method which is language independent but requires a large amount of data to obtain precise results. The second is a Rule based approach which uses various language dependent rules to remove the affixes. It exploits grammatical rules pertaining to one specific language $\&$ hence is language dependent. Also developing rule based stemmers for each language is very time consuming and expensive. The third method is a cluster based approach \& we use this method for our purpose.

Unsupervised Morphology Acquisition Method proposed in [1] is one of the most prominent and classic probabilistic stemming methods. It is based on Minimum description length (MDL) concept. The input is represented as a sequence of distinct numeric values in the smallest possible number space. But it works well only for the English script (Roman). The implementation of this algorithm can be done by the freely available software- 'Linguistica'. The work proposed by [2] focuses on the development of an unsupervised stemmer for Hindi. It uses the split-all method which is partly similar to that of [1]. Although Probabilistic approach is language independent, but often, acceptable results are obtained only for vast data set.

Stemmer designed by [10] is one of the most cited stemmers for English. It is based on predefined hand crafted suffix replacement rules. A handcrafted rule based approach to stemming alone, for Hindi was proposed in [3]. It introduces an approach which is essentially a suffix stripper, taking into account the noun, adjective and the verb inflections occurring in Hindi. The proposed stemmer strips off word suffixes from the suffix list on the longest match basis. Stemmer for Punjabi given in [4] uses the concept of brute force. It employs a look up table which contains relations between root forms and inflected forms. To stem a word, the table is queried to derive the matching inflection. If a matching inflection is found then the root form is returned. Another rule based application is with paradigm approach introduced in [5], in which to permit rapid matching of suffixes and root word, trie data structure is adopted. We would like to point out that, since rule based methods are language dependent, they come with an overhead of requiring modifications for being scalable to other languages.

The clustering approach involves unsupervised classification of data into various clusters. A similar method was proposed by [8], which used four distance measures for clustering the words. The clustering technique used complete linkage clustering algorithm which belong to class of hierarchical clustering. The work, however, aimed to improve accuracy of IR. The algorithm was tested for English, Bengali and French. Although more effective in comparison to other methods, the algorithm required empirical evaluation of a number of clusters, and a choice of an appropriate threshold to get accurate clusters. Another approach introduced by [9] combines statistical approach and clustering to improve stemming. This algorithm breaks a word in all possible locations given the maximum suffix length and minimum stem length and filters out the important decompositions on the basis of frequency of occurrence. It performs clustering by k-mean algorithm using CLUTO tool. K-mean requires that, one specified the number of cluster to be created. This aspect brings sufficient rigidity to introduce error in clustering. Also, it cannot be effective in case of varying data set as each may require different number of predefined clusters. On contrary, the method of hierarchical clustering automatically builds the needed clusters. Only overhead is, the choice of wise threshold.

Previous works in lemmatization such as that developed by [11] do not produce noteworthy \& significant precision and recall. In the papers proposed by [12] and [13], the lexicon extraction involves incremental or post-construction manual validation of entire lexicon. Besides, in these works, forgoing the language knowledge at primary level is indispensable.

The algorithm we propose, concentrates on stemming in majority, and in addition we have explored the possibility of fusing lemmatization to minimize over-stemming. In effect we aim to create a stemmer-lemmatizer hybrid. The introduced lemmatization exploits only the corpus based heuristics instead of linguistic information, for improving the parameters governing the accuracy delivered by the proposed system. The distinctive features that our proposition offers is noteworthy in that it yields exceptional results on both vast and small data sets, the later being a bottleneck of the statistical approaches to stemming. It also relives from the overhead of framing deliberately crafted rule base which is vital for handling both under-stemming and over-stemming. The aspect of prime distinction is the introduction of lemma, without using word class information, in supervised stemming which goes a long way in preventing over-stemming.

\section{PROPOSED ALOGORITHM}

As stated earlier, our work attempts to improve the quality of the stemming with the introduction of lemmatization. We have used the split-all method, \& the primary steps align with those in [9]. However, we present a different and of course a 
better grouping criteria to encompass the cluster approach to stemming that yields better results for Hindi. The schematic diagram of the algorithm is shown in Figure 3 and the following lines describe all the steps of our algorithm in detail, along with appropriate examples.

\subsection{Steps of the Algorithm}

Step 1: Preprocessing

Read the input corpus to convert different encoded texts to a common encoding scheme viz. UTF8. It is necessary to clean the data by removing punctuations $(!,: ;$ ? “"( ) \{\}[]$\backslash /+-$ $\%)$, digits special characters and English characters.

Step 2: Create a unique word list.

The sentences are tokenized to word level to create a unique words list. From the file, the different words delimited by space, tab or line is to be obtained. Thus, this step essentially involves feeding a raw text file to obtain a list of unique words in it.

Step 3: Decompose the word list into stems and suffixes. Each word obtained is checked and is decomposed into all possible stems and suffixes assuming maximum length of suffix, max_suffix_length $=8$ and minimum length of the stem, min_steml_ength $=2$. Below @ represents the NULL character. It indicates that this split appears as such in the data set, \& that the corresponding stem can also be a root word.

For example: लडकियो: (English Translation: "girls")

लड+कियो; लडक+ियो; लडकि+यो; लडकिय+ो; लडकियो+@\}

Step 4: Collect suffixes for each stem.

The data is sorted and formatted such that a particular stem is displayed with all the possible suffixes it can occur with. The bag of suffixes for each stem is identified using the procedure given in Figure 1.

Illustration: Consider the set \{लडकी, लडकियाँ, लडकियो\}. Application of step 4 to it should yield:

\{लड: की, कियाँ, कियो\}, \{लडक: ी, ियाँ, ियो\}, \{लडकि:याँ, यो\}, \{लडकिय: ाँ, ो\}, \{लडकी: @\}, \{लडकियाँ: @ \}, \{लडकियो: @ \}

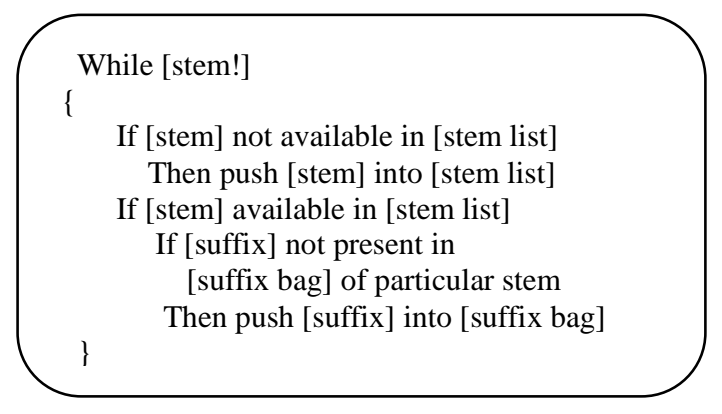

Fig1: Procedure done in step 4.

Step 5: Frequency based elimination of stems

Verify the obtained stem and suffix bag to find the frequency of occurrence of each stem. A particular threshold frequency, here 2 , is selected to eliminate all the frequency below it i.e., all stems not appearing with more than two suffixes are removed.
Step 6: Frequency based elimination of suffixes

Like step 5 all the suffixes that have not occurred with more than two stems are to be eliminated.

\section{Step 7: Grouping Criteria}

A new grouping criterion has been introduced to cluster the similar stems.

a) Among similar decompositions, the one which has smallest stem is selected. Next, for each stem $S$ another stem $t$ is identified such that $S$ can be obtained by appending some word $u$ to $t . s=u+t$. If there is more than one choice for $t$ then the shortest should be selected.

Illustration: Consider the stems: आलड, लडक, लडकि, लडकिय, लडकियॉ $\}$ the stem लडकियॉ contains लडकिय+ॉ; लडकि + यॉ; लडक+ियॉँ; लड+कियॉ, so the stem "लड" which is the shortest is selected.

b) To achieve lemmatization, the decomposition with the @ is selected, i.e. the decomposition having the stem which has occurred as such in corpus is taken as lemma.

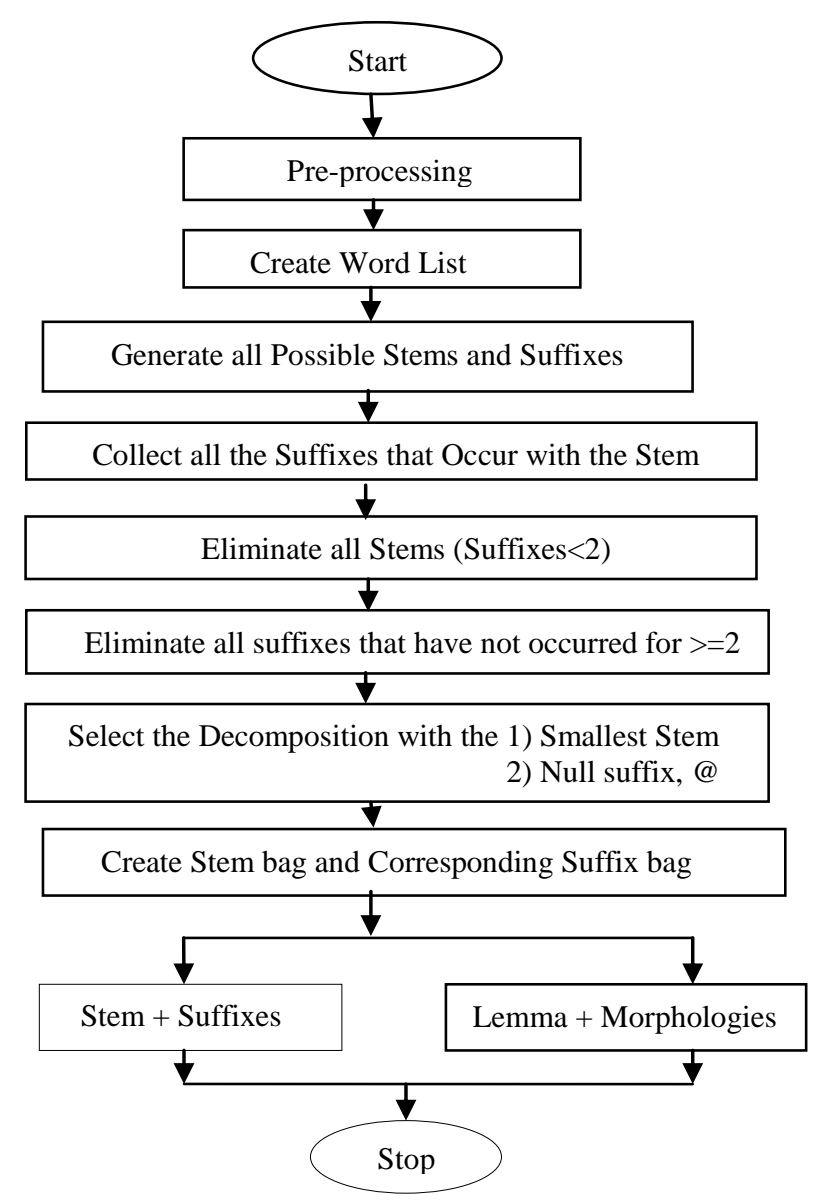

Fig2: Schematic diagram of the proposed algorithm

Step 8: Create stem bag and suffix bag

By checking which all suffixes that have the same suffix set, the stem bags and corresponding suffix bags are to be created. 
Step 9: Generation of output

Using all the above steps the required output is obtained in the following form:

$$
\begin{aligned}
& \text { Stem + suffixes } \\
& \text { Lemma + Morphologies }
\end{aligned}
$$

The above algorithm is summarized in the layout of a flow chart in Figure 2. The flow chart describes the schema in a comprehensive manner.

To get a better understanding of the fore mentioned steps, some of the sample outputs are illustrated in the following subsection.

\subsection{Illustration}

A sample data containing 32 unique Hindi words is used to analyze the output which is shown in Figure 3. The first few steps are space consuming $\&$ are thus not included here. The needed illustrations for those steps, however, have been appropriately appended with the steps of the algorithm.

लडका, लडकी, लडकियाँ, लडकियों, सच्चे, सच्चा, सच्ची, सच्चाई, सच्चाइयों, सच्चाइयाँ, अच्छा , अच्छाई, अच्छाइयाँ, अच्छाइयों,खाना , खाता, खाया , खाएगा, जीना, जीता, जीया, जीएगा, ईमानदार, ईमानदारी, चौकीदार, चौकीदारी, कहानी, कहानियाँ कहानियों, कहावत, कहावतों, कहावतें

Fig3: The sample data set

\subsubsection{Grouping of stems and suffixes}

From the above given sample data set the stems and suffixes are separated as shown below, using Step 7:

\begin{tabular}{|c|c|}
\hline Stems & Suffixes \\
\hline अच्छ & ा|ाइयॉ|ाइयो|ाई \\
\hline अच्छा & @|इयॉ|इयो|ई \\
\hline ईमान & दारादारी \\
\hline ईमानदार & @ ी \\
\hline चौकी & दारादारी \\
\hline चौकीदार & $@$ \\
\hline कहान & ियॉ|ियो|ी \\
\hline कहावत & ो||@ \\
\hline जी & ना|ता|या|एगा \\
\hline खा & ना|ता|या|एगा \\
\hline लडक & ा|ी|ियॉ|ियो \\
\hline सच्च & ा|ी|ाई|ाइयॉ|ाइयो|) \\
\hline सच्चा & @ |ई |इयॉ |इयो \\
\hline
\end{tabular}

Table1. Separated stems and suffixes

\subsubsection{Creation of stem and suffix bags}

The obtained stems and suffixes are to be evaluated. Using step 8 stem bags and suffix bags are generated as follows:
अच्छ

अच्छा, सच्चा

ा|ाइयाँ|ाइयों|ाई

ईमान, चौकी

@ इयाँ|इयों|ई

ईमानदार, चौकीदार

दार|दारी

कहान

@

ियाँ|ियों|ी

कहावत

ो|ं।

खा, जी

ना|ता|या|एगा

लडक

ा|ी|ियाँ|ियों

सच्च

ा|ी|ई|ाइाँ|ाइयों|े

It is evident from the above list that, different stems with same suffixes set are grouped together. For example "ईमान", "चौकी" are grouped together since they are having common set of suffixes "दार", “दारी” .

\subsubsection{Outputs for stemming and lemmatization}

Separate stemming and lemmatization outputs are obtained after the step 9. This list is presented below:

\begin{tabular}{|c|c|}
\hline अच्छ & ा|ाइयॉ||ायो|ाई \\
\hline ईमान, चौकी & दार|दारी \\
\hline कहान & ियॉ|ियो|ी \\
\hline खा, जी & ना|ता|या|एगा \\
\hline डक & ा|ी|ियॉ|ियो \\
\hline & ा|ी|ाई \\
\hline
\end{tabular}

Stemming:

Lemmatization:

अच्छा, सच्चा

ईमानदार, चौकीदार

@ इयॉ|इयो|ई

कहावत

(a)

ो||@

From the obtained results it is evident that the stemmer exhibits appreciably high degree of accuracy. Noteworthy stemming occurs in case of "कहानी" and "कहावत". The two semantically apart words have been put in separate groups as required, which could not be achieved by any other existing clustering techniques. Even Linguistica software could not furnish this desirable result. Such is the genre of stemming required to improve the accuracy of IR system. Clearly, the proposed algorithm succeeds in improving the stemming, and reduces the over-stemming problem by the introduction of lemmatization. An aspect of prime importance is that, no linguistic input was required for the lemmatization to be done accurately.

The results thrown up by our stemmer has been exceptional, when compared to other existing stemmers. This however, was on the sample data set which was designed by us. In order to completely validate the effectiveness of our algorithm, we need to expose it to a random corpus. The next section describes the corpus used for the validation. 


\section{CORPUS CONTOUR}

We present a brief description of the corpus that we have used to prove the excellence delivered by our algorithm here. The statistics pertaining to the data set is presented in Table 2. In order to show where our algorithm stands, we have adopted a double check measure. Not only did we select a random corpus but also compared our results vis-à-vis that produced by linguistica software which is based on the commonly used technique of stemming.

As regards to data sets, one is from the EMILLE corpus [2], having 67340 running words \& 6354 unique words, \& the other has been extracted from Hindi translation book corpus which is in-home built. The later has 9056 running words \& 1328 unique words.

Table 2: Statistics of data set

\begin{tabular}{|l|c|c|}
\hline \multirow{2}{*}{ Data statistics } & \multicolumn{2}{|c|}{ Training data } \\
\cline { 2 - 3 } & $\begin{array}{l}\text { Hindi translation } \\
\text { book corpus }\end{array}$ & $\begin{array}{l}\text { EMILLE } \\
\text { corpus }\end{array}$ \\
\hline $\begin{array}{l}\text { No. of running } \\
\text { words }\end{array}$ & 9056 & 67,740 \\
\hline Unique words & 1328 & 6354 \\
\hline Min. length & 2 & 2 \\
\hline Max. length & 10 & 18 \\
\hline
\end{tabular}

The succeeding section gives a detailed account of evaluation performed on the proposed algorithm.

\section{EXPERIMENTATION}

From the results obtained it is seen that the our algorithm gives more promising outputs when compared to Linguistica in terms of number of stems, suffixes \& the signatures. A signature corresponds to the suffix bag a particular stem takes. The statistics of outputs obtained from the proposed method and Linguistica are presented in Table 3 and Table 4, respectively. Suffixes in fact, are more effectively identified by the proposed approach. Linguistica being a probabilistic approach, with less frequency of words, its performance degrades as shown in the tabulation. The same is justified in the lines below.

Table 3: Stemming statistics by proposed algorithm

\begin{tabular}{|l|l|l|}
\hline \multirow{2}{*}{ Data Statistics } & \multicolumn{2}{|c|}{ Training data } \\
\cline { 2 - 3 } & $\begin{array}{l}\text { Translation } \\
\text { Book corpus }\end{array}$ & EMILLE corpus \\
\hline Stems & 323 & 1609 \\
\hline Lemma & 87 & 463 \\
\hline Suffixes & 1227 & 6905 \\
\hline Signatures & 235 & 1055 \\
\hline Pruned out words & 102 & 367 \\
\hline
\end{tabular}

Table 4: Stemming statistics by Linguistica

\begin{tabular}{|l|l|l|}
\hline Data Statistics & \multicolumn{2}{|c|}{ Training data } \\
\cline { 2 - 3 } & $\begin{array}{l}\text { Hindi translation } \\
\text { Book corpus }\end{array}$ & $\begin{array}{l}\text { EMILLE } \\
\text { corpus }\end{array}$ \\
\hline Stems & 28 & 612 \\
\hline Suffixes & 5 & 406 \\
\hline Signatures & 5 & 80 \\
\hline Pruned out words & 1297 & 4380 \\
\hline
\end{tabular}

A matter of immense remark is derived from Table 3 and Table 4 where in the amount of pruned out words with our algorithm is far too less when compared to the number found in case of linguistica. For instance, Linguistica could not provide - "पिता", “मात्रा", \& “युवा" as stems, where as the new algorithm delivered results in precise (Ex.19 in Table 6). The prominent \& probably the only reason attributed to the fail factor of linguistica is its method of working which is largely frequency dependent $\&$ its need for vast data set to deliver acceptable results. However, no such conditions restrict the functioning of our algorithm. The success factor of our algorithm is its all new criteria that its works on besides the crux of the proposed concept i.e., stemming with partial fusion of lemmatization. A point to note in this regard is that, Linguistica gives no explicit information about the lemma. Some samples of stems \& signatures as obtained from Linguistica and the proposed algorithm are presented in Table 5 and Table 6, respectively. Another striking aspect in the comparative study of our algorithm versus Linguistica comes from the fore mentioned tabulation, where in the count of suffixes for a given stem bag and /or the count of stems for a given suffix bag is beyond an appreciable margin in results produced by our algorithm. For the purpose of worthwhile notice, the former is observed in Ex.6 vs. Ex.14 from the Table $5 \& 6$, respectively, \& the later is explicit from Ex.5 vs. Ex.5. We attribute this to a novel stemming criterion as proposed in Section 3.

We close the comparative study by highlighting an important factor that distinguishes our approach from almost all the existing stemming or lemmatization works. It is that, we have used UTF-8 encoding scheme \& worked directly on the Devanagari script. Clearly, the overhead of transliteration does not show up with the proposed algorithm, which is always the case in nearly all existing stemmer from South Asian languages. While many of the south Asian languages derive its existence from the same script, our algorithm can be effectively extended to these languages $\&$ is hence scalable.

Table5: Samples produced by Linguistica

\begin{tabular}{|c|c|c|}
\hline Ex. & Stems bag & Suffix bag \\
\hline 1. & आइए ,चुके, हूँ, करूँ, रखिए & गा, @ \\
\hline 2. & खे & $\begin{array}{l}\text { लूगाँ,ली,ला,लना,लते, } \\
\text { लती,लता,ल }\end{array}$ \\
\hline 3. & अकेले, चिड़चिड़ा & पन, @ \\
\hline 4. & भावना, सूचना & त्मक,एँ,ओं, @ \\
\hline 5. & आरम्भ,तत्काल, प्रारंभ, वास्तव & िक,@ \\
\hline 6. & दिख & $\begin{array}{l}\text { ाया, ाना, ाते, ाएँ, ा, } \\
\text { ने,ना,ते,ती,@ }\end{array}$ \\
\hline 7 & $\begin{array}{l}\text { अवस्था,असमानता,चिंता, } \\
\text { दशा,शिशु,सत्ता,सफलता,कक्षा }\end{array}$ & ओं,@ \\
\hline 8. & $\begin{array}{l}\text { जाँचें, जाएँ, जाएँ, जायें, पाएँ, } \\
\text { पायें, रहें, सीखें }\end{array}$ & गे,@ \\
\hline 9. & आन,खड,नीच,पीत,मीठ,रह & ।, \\
\hline 10. & आग & े,रा,@ \\
\hline
\end{tabular}


In spite of promising efficiency of our system, there are errors which have crept into some results. For instance, in Ex 9, “चा" + [obtained signature] is not a proper decomposition. We would like to emphasize that, it however is not the fault of the proposed algorithm. This is because, in stemming point of view, the result is perfect. The problem lies only in the fact that the result is semantically incorrect. Another problem of the same genre is encountered in Ex. 3 where in the stem "आग" means "fire", but "आगरा" meant a name of a "place", \& “आगे" will mean "forward". Thus, the appropriate result should have been as follows: Stem bag $=\{$ आग, आगरा, आगे $\}$ and suffix $=\{@\}$.

Clearly, the fore mentioned cases \& few more issues of such type can be effectively handled by some kind of post processing. The next section aims to rectify these problems based on heuristics which completely rely on corpus for its working.

\section{EXPLOITING HEURISTICS}

Heuristics exhibit sufficient potential to increase the effectiveness of the algorithm. This subsection explores some such heuristics, most of which can work well for other languages as well and are hence scalable. We present the heuristics in an appropriate structure \& with easy notations, which make them perfectly convenient to be translated to any programming language, for the purpose of implementation.

\section{Rule1. Atomizing the signature list.}

Let $\alpha$ denote the set of signatures that a stem bag $S$ can assume. In set builder form, we define $\alpha$ as:

$$
\alpha=\left\{\alpha_{i} \mid \alpha_{i} \in \text { signature of } S, \& i \in N\right\},
$$

where $\mathrm{N}$ is the set of positive integers. Consider $\beta_{i}, i \in N$; which consists of sets of $\alpha_{i}$ that are decomposed at character level, i.e. consonants and vowels.

$$
\beta_{i}=\left\{\alpha_{i j} \in\right. \text { characters }
$$

$\left.\alpha_{i}, \& i \in N, j \in N\right\}$.

The set $\beta_{i}$ is the ordered set of characters of $\alpha_{i}, i \in N$. Let $\beta$ denote the collection of all $\beta_{i}$ of $S$.

Now, if $u=\bigcap_{i \in N} \beta_{i} \neq \phi$

Then $S^{\prime}=S+u$, where $S^{\prime}$ is the modified stem bag of $S$, and the revised signature list is obtained by performing $\rightarrow$ $\left(\alpha-u_{i}\right), \forall i \in N$.

Rule2. Applying divide \& conquer rule on atomized signatures

Consider the previously obtained set $\beta$.

Let $u_{1}=\beta_{1} \cap \beta_{2} \neq \phi$.

If $u_{1} \cap \beta_{p+1}=u_{1}, \quad \forall p \in N-\{0,1\}$

Skip the below mentioned

Else

Store $u_{1}$

\begin{tabular}{|c|c|c|}
\hline Ex. & Stem bag & Suffix bag \\
\hline 1. & आए, खाए,सोए & गाँ, ॉगे, @ \\
\hline 2. & आओ,करें,करो, चलें,पिये, बोलो & गे,@ \\
\hline 3. & आग & े,रा,@ \\
\hline 4. & आन,खड,नीच, पीत,मीठ,रह & बा \\
\hline 5. & $\begin{array}{l}\text { आरंभ,आरम्भ,तत्काल,प्रारंभ, } \\
\text { मास,वास्तव,समाज }\end{array}$ & िक,@ \\
\hline 6. & $\begin{array}{l}\text { उपयोग,गवाह,डाक्टर,विदेश, } \\
\text { सरकार }\end{array}$ & ী,,@ \\
\hline 7. & संस्था & $\begin{array}{l}\text { यों, यें, ये, ओं, } \\
\text { एं,एँ, @ }\end{array}$ \\
\hline 8. & अपेक्षा & कृत|ओं|एँ|@ \\
\hline 9. & चा & चा,ट,र,य,बी \\
\hline 10. & खे & $\begin{array}{l}\text { लूगा,ली,ला,लना,ल } \\
\text { ते,लती,लता,ल }\end{array}$ \\
\hline 11. & आप & के,की,को, से,सी,सा \\
\hline 12. & आपस & े, ी, @ \\
\hline 13. & दण्ड,प्रकाश & ित,@ \\
\hline 14. & दिख & $\begin{array}{l}\text { ाया, ाने, ाना, } \\
\text { ते, ाएँ, ाई, } \\
\text { ाइए, ा,ने,ना,ते, } \\
\text { ती,@ }\end{array}$ \\
\hline 15. & $\begin{array}{l}\text { करन,कितन,भरन,मेर,रहत,लगत, } \\
\text { लात,लेत,सीध,होन }\end{array}$ & बी, ा \\
\hline 16. & ठेके,रिश्ते & दारों,दार,@ \\
\hline 17. & अकेले,चिडचिडा,थलना, पागल & पन,@ \\
\hline 18. & भावना,सूचना & त्मक,ओं,एँ,@ \\
\hline 19. & $\begin{array}{l}\text { अवस्था,असमानता,कक्षा,चिंता, } \\
\text { दशा,पिता,मात्रा,युवा,शिशु,सत्ता, } \\
\text { सफलता }\end{array}$ & ओं,@ \\
\hline 20. & $\begin{array}{l}\text { करायें,चाहें,जाँचें,जाएँ,जाएं, } \\
\text { जायें,पाएँ,पायें,रहें, सीखें }\end{array}$ & गे,@ \\
\hline
\end{tabular}

Table6: Samples produced by proposed algorithm

Capture $\beta_{p+l}$ in $u_{2}$, where $p \in$ the index at which mismatch occurred.

Restart

These steps will divide the signature into group viz. $u_{i}, \forall i \in N$, and there by dividing the atomized list. Now find the following:

$$
S^{\prime}=S+u_{i}, \forall i \in N \text {, And thus revise the stem }
$$
\& signature list. 


\section{Rule3. Redundancy removal}

Compare $S^{\prime}$, obtained after Rule2, against all the stems in the stem list. Incase of a found match, merge the signatures of $S^{\prime}$ and $S$. In order to reduce the computational complexity and time, as a rule of thumb, if $\alpha^{\prime} \subset \alpha$, then merge the elements of $\alpha^{\prime}$ with $\alpha$. Reciprocate the statement for the other cases.

Rule4. Special case of signature list reduction

Only to reduce the complexity of computation, this step expects that all the above steps have been performed. Consider the revised set of signatures. Lets call it $\alpha$, again. Note that it may be different from the $\alpha$ of rule 1 . Now we define another set $\theta$, as shown below.

$\theta=\left\{\alpha_{i} \mid \alpha_{i} \in\right.$ vowels with length $\left.\leq 2, i \in N\right\}$. If $\theta \neq \phi$, then modify the corresponding stem bag as $S^{\prime}=S+\theta_{i}, \forall, i \in N$ where $\theta_{i}$ are the members of the set $\theta$. Finally, the revised signature list is obtained by performing $\rightarrow\left(\alpha-u_{i}\right), \forall i \in N$.

\section{Rule5. Special case of stem modification}

Consider the stem \& signature list. In the stem list, capture all the instances where only one stem occurs but has its corresponding signatures in multiple.

For each stem bag $S$ of such type, capture the corresponding suffix bag (also called signature) $\alpha$, in a manner same as that in Rule1. Next, evaluate the following:

If $\bigcap_{i \in N} \beta_{i}=\phi, \quad \forall i \in N$,

and each $\beta_{i} \in($ consonants + vowels (length $\left.\leq 2)\right)$, then obtain the modified stem bag as $S^{\prime}=S+\alpha_{i}, \forall \alpha_{i}$ whose $\beta_{i}$ satisfies the above condition; $i \in N$.

After applying the fore mentioned heuristics on the results produced by our algorithm, the statistics of the results showed noteworthy improvements \& the same have been tabulated below in Table 7.

Table7: Proposed algorithm+ post heuristic output

\begin{tabular}{|l|l|l|}
\hline \multirow{2}{*}{$\begin{array}{l}\text { Data Statistics } \\
\text { output }\end{array}$} & \multicolumn{2}{|c|}{ Training Data } \\
\cline { 2 - 3 } & $\begin{array}{l}\text { Translation } \\
\text { Book corpus }\end{array}$ & EMILLE corpus \\
\hline Stems & 380 & 1978 \\
\hline Lemma & 93 & 738 \\
\hline Total Suffixes & 1208 & 5212 \\
\hline Signatures & 211 & 1019 \\
\hline Pruned out words & 102 & 367 \\
\hline
\end{tabular}

The tabulation shows that the numbers of stems \& lemmas have increased in comparison to corresponding statistics displayed in Table 3, after applying the heuristics. A better insight to the obtained results can be derived from the next section that calculates the various metrics which shows the efficacy of our system.

\section{RESULTS \\ AND \\ STATISTICS}

ANALYSIS

After having run the algorithm over the test data set, we randomly choose 100 words from Hindi translation book corpus \& 500 words from EMILLE corpus. The choice, though random was made on a pool of words satisfying an important criteria viz. the occurrence of these words in the corpus had a minimum frequency of 2 . We manually verified the results using the standard measures of effectiveness evaluation viz. Recall, Precision and F-score. These measures utilized for effectiveness evaluation are computed in the manner shown below:

$\%$ Recall $(\mathrm{R})=\quad($ total no. of correct decomposition given by the system *100)

(Total no. of correct decomposition)

$\%$ Precision $(\mathrm{P})=$

(Total no. of correct decomposition given by the system *100)

system)

(Total no. of decomposition given by the

F-score $=\frac{2 * \mathrm{R} * \mathrm{P}}{(\mathrm{R}+\mathrm{P})}$

Table $8 \& 9$ display these metrics as obtained when the test data set was run through the proposed system followed by the heuristics and through linguistica, respectively.

Table8. Test results from proposed algorithm+post processing

\begin{tabular}{|l|l|l|l|}
\hline Test data sets & Recall \% & Precision \% & F-score \% \\
\hline 100 words & 95.133 & 96.831 & 95.974 \\
\hline 500 words & 96.063 & 97.395 & 96.724 \\
\hline
\end{tabular}

Table9. Test results from Linguistica

\begin{tabular}{|l|l|l|l|}
\hline Test data sets & Recall \% & Precision \% & F-score\% \\
\hline 100 words & 20.623 & 34.964 & 25.944 \\
\hline 500 words & 60.674 & 76.198 & 67.978 \\
\hline
\end{tabular}

The values of the above metrics achieved not only beat those of the existing stemmers but also is ahead of the corresponding values obtained by linguistica, and by an exceptionally huge margin. Significantly low value of recall $\&$ precision in case of later is due to large number of pruned out words. This does not occur in our case on account of the novel stemming criterion devised.

Besides these measures, we also evaluated the results by computing the number of under-stemming errors and overstemming errors for both of the test data sets in order to align, in particular, with our claim of having achieved lower degree of over-stemming. They are calculated as follows: stemming errors for both of the test data sets in order to align, in particular, with our claim of having achieved lower degree of over-stemming. They are calculated as follows:

$\%$ under-stemming error $=$

(Total no. of variants not conflated by the stemmer *100) (Total number of morphological variants)

$\%$ over-stemming error $=$

(Total no. of non-variants conflated by the stemmer $* 100$ ) (Total number of words conflated by the stemmer) 
The results obtained for the above mentioned statistics are displayed in Table 10.

Table10. Test results from proposed algorithm+post processing

\begin{tabular}{|l|l|l|}
\hline Test data sets & $\begin{array}{l}\text { \%under-stemming } \\
\text { error }\end{array}$ & $\begin{array}{l}\text { \%over-stemming } \\
\text { error }\end{array}$ \\
\hline 100 words & $1.07 \%$ & $5.24 \%$ \\
\hline 500 words & $0.91 \%$ & $4.13 \%$ \\
\hline
\end{tabular}

The above tabulation makes it explicit that the stemming errors, over-stemming in specific, has got sufficiently suppressed. However, no comparison could be made against any of the existing works either because they the do not use this metric or due to platform variations viz. usage of different corpus of efficacy evaluation, varying amounts of words chosen as the test set, etc. After attaining \& describing the overwhelming results submitted by our system, we close the discussion of our proposition \& result analysis here.

\section{CONCLUSION AND FUTURE WORK}

The concept proposed in this paper is one of a kind. The idea aims to fuse shallow lemmatization in unsupervised stemming which has never been explored for Hindi thus far. The results thrown up by this concept has demonstrated significant potential in handling inflectional morphology. The algorithm adopts the cluster based approach. The algorithm, however overcomes the problem of empirically determining the number of clusters. Among the output the lemmas and stems can be separated. Also it works well on small data sets and it evidently is language independent. Of several features of distinction that our proposition offers, the most important is the hybridization of lemmatization with unsupervised stemming. In particular, we aimed to minimize overstemming problem through our approach by the use of lemmatization which does not need any word class information.

It becomes explicit from above results that our stemmer yields far more appealing \& promising results when compared to linguistica, and the same is achieved by a good margin when compared to other existing propositions, not only in terms of number of stems, corresponding signatures \& suffixes but also in terms of widely accepted standard measures. The figures obtained for these metrics validate the efficacy of our proposition. And all this comes with no overhead of transliteration, as our algorithm has been designed to work directly on the Devanagari script. Since many other South Asian Languages derive its origin from the same script, our algorithm without any doubt, can be extended to all those languages. Our future work shall explore the fore mentioned novel scalability, along with the investigation of the avenues that would further improve the parameters that govern the accuracy of our algorithm.

\section{ACKNOWLEDGMENTS}

Our thanks to Aswathi for creating the sample database that was used for primary evaluation of our algorithm. Also we thank Vani, who spent sufficient time on proof reading of our manuscript.

\section{REFERENCE}

[1] John goldsmith, 2001, Unsupervised learning of the morphology of a Natural language, Computational Linguistics, Volume 27, No. 2 pp. 153-198, 2001

[2] Amaresh Kumar Pandey, Tanveer J Siddiqui, 2008, An unsupervised Hindi Stemmer with heuristic improvements, In Proceedings of the second workshop on Analytics for noisy unstructured text data, 2008,pp 99-105, Singapore.

[3] A Ramanathan and D.D Rao, 2003. A Light weight Stemmer for Hindi. In processing of the $10^{\text {th }}$ conference EACL, on Computational Lingusitics for South Asian Language, Budapest Hungary.

[4] Dinesh Kumar and Prince Rana, 2001, Stemming of punjabi words by using brute force technique, International Journal of Engineering Science and Technology (IJEST).

[5] Shambhavi. B. R, Dr. Ramakanth Kumar P, Srividya K, Jyothi B J, Spoorti Kundargi, Varsha and Shastri G, 2011, Kannada Morphological Analyser and Generator Using Trie, IJCSNS International Journal of Computer Science and Network Security

[6] A.K. Jain, M.N. Murty and P.J. Flynn, 2000, Data Clustering: A Review, ACM Computing Surveys.

[7] Information Retrieval, Chapter 16,17, 2009, Cambridge University Press

[8] Prasenjit Majumder, Mandar Mitra, Swapan K.Parui and Gobinda Kole, 2007, YASS: Yet Another Suffix Stripper, ACM Transactions on Information Systems,Vol.25, No.4, Article 18

[9] KVN Sunitha and N Kalyani, Sadhana, 2009 Improving Word Coverage using unsupervised morphological analyzer, Indian Academy of science

[10] M. F. Porter, 2006 An algorithm for suffix stripping, Program: electronic library and information systems, vol.40, pp. 211-218,

[11] Antoni Oliver, Marko Tadic. 2004. Enlarging the Croatian Morphological Lexicon by Automatic Lexical Acquisition From Raw Corpora. In Proceedings of LREC 2004, Lisbon,Portugal.

[12] Benoit Sagot. 2007. Building a Morpho-syntactic Lexicon and a Pre-syntactic Processing Chain for Polish". In Proceedings of LTC 2007,Poznan, Poland. I

[13] Markus Forsberg, Harald Hammarstrom and Aarne Ranta. 2006. Morphological Lexicon Extraction from Raw Test Data. In Proceedings of the $5^{\text {th }}$ International Conference on Advances in Natural Language Processing. 